\title{
Akrilik Capping Modifikasyonlu Twinblok Alt Keser Proklinasyonunu Engelliyor mu?
}

\section{Does Acrylic Capping Modification Twin Block Inhibit The Proclination of Lower Anterior Teeth}

\section{ÖZ}

Amaç: $\mathrm{Bu}$ araştırmanın amacı; Twinblok (TWB) apareyinin iki farklı dizaynının alt keser dişlerin konumları ve açılarına olan etkilerini incelemek ve karşılaştırmaktır.

Gereç ve Yöntem: Araştırmamızda büyüme ve gelişim döneminde bulunan, Sınıf II Bölüm 1 maloklüzyona sahip toplam 30 birey dahil edilmiștir. Bireyler, alt keser bölgesinde akrilik veya kroşe içeren TWB apareyi uygulanmak üzere rastgele 2 gruba ayrılmıștır. Bireylerden tedavi öncesi (T0) ve tedavi sonrasında (T1) alınan sefalometrik filmlerin analizi ile alt keser dişlerde meydana gelen değişiklikler değerlendirilmiştir. Verilerin analizinde Shapiro Wilk ve Çift yönlü varyans analizi kullanılmıştır.

Bulgular: Her iki grupta da Tl'de alt keser konumlarını ifade eden tüm ölçümlerde istatistiksel olarak anlamlı fark bulunmuştur ( $\mathrm{p}<0,005)$. Gruplar arasında ise T1'de; IMPA, L1/NB ve Md1/MdOP açısal değerlerinde istatistiksel olarak anlamlı fark bulunmuştur $(\mathrm{p}<0,005)$.

Sonuç: TWB apareyinin alt keserlerde akrilik cappingli dizaynının alt keser proklinasyonunda etkili olduğu bulunmuştur.

Anahtar sözcükler: Twin Block, Alt keser, Sınıf II tedavi.

\section{ABSTRACT}

Aim: The purpose of this research was to examine and compare the effects of two different designs of the Twin-Block (TWB) appliance on the position and angle of the lower anterior teeth.

Material and Method: A total of 30 individuals during the peak pubertal period with Class II Division 1 malocclusions were included in our study. Individuals were randomly divided into 2 groups to apply the TWB appliance containing acrylic or clasps on the lower anterior teeth. The analysis of cephalometric films of individuals were evaluated at pre-treatment (T0) and post- treatment (T1) to determine the changes of the lower anterior teeth. Shapiro Wilk and two-way ANOVA analysis were used for the analysis of the data.

Results: Statistically significant difference was found in all measures expressing lower teeth positions at $\mathrm{T} 1$ in both groups $(\mathrm{p}<0.005)$. Among the groups at $\mathrm{T} 1$; IMPA, L1/NB and Md1/MdOPangular values were found statistically significant $(\mathrm{p}<0.005)$.

Conclusion: It was found that the acrylic capping design of the TWB appliance was effective on the lower anterior teeth proclination.

Key words: Twin Block, Lower teeth, Class II treatment.
Burcin AKAN

Gökçenur GÖKÇE

İzmir Katip Çelebi Üniversitesi

Diş Hekimliği Fakültesi,

Ortodonti Anabilim Dalı, İzmir, Türkiye

Geliş tarihi / Received: 11.07.2017

Kabul tarihi / Accepted: 19.09.2017

DOI: $10.21306 /$ jids.2018.1.37
İletişim Adresi/Corresponding Adress:

Burçin AKAN

İzmir Katip Çelebi Üniversitesi

Diş Hekimliği Fakültesi,

Ortodonti Anabilim Dalı, İzmir, Türkiye E-posta/e-mail: burcin.yksel@gmail.com 


\section{GíRiş}

Sınıf II maloklüzyonlar popülasyonda sıklıkla görülen bir maloklüzyon tipidir. Literatürdeki epidemiyolojik çalışmalarda, Avrupa ve Kuzey Afrika toplumlarında Sinıf II görülme oranını \%20'nin üzerinde olduğu rapor edilirken Asya, Orta Doğu ve Latin Amerika'da bu oranın \%10-15 arasında olduğu bildirilmektedir. Ülkemizde yapılan epidemiyolojik çalışmalara göre, tüm maloklüzyonlar içerisinde Angle Sinıf II Bölüm 1 maloklüzyonun görülme sıklığının \% 15.9-19 arasında değiștiği ve Sınıf I maloklüzyonlardan sonra en sik karşılaşılan ikinci maloklüzyon tipi olduğu belirtilmiştir $(1,2)$. Bu maloklüzyonlar; iskeletsel, dental veya her ikisinin kombinasyonu şeklinde karşımıza çıkabilmektedir (3). İskeletsel kaynaklı olan Sınıf II maloklüzyonların tedavisinde sıklıkla fonksiyonel apareylerden yararlanılmaktadır (4). Fonksiyonel apareyler, mandibulanın vertikal ve sagittal olarak konumunu değiştirerek oluşan kas kuvvetleri ile ortopedik ve ortodontik değişimler meydana getirirler (5).

Fonksiyonel çene ortopedisinde kullanılan apareyler, tedavi felsefeleri ve teknik özellikleri bakımından farklılık gösterseler bile bu apareylerin hepsi mandibulanın ileride konumlandırılmasına yönelik fonksiyon gördükleri noktasında birleşmektedir. Sınıf II Bölüm 1 maloklüzyonların düzeltilmesinde en sık kullanılan hareketli fonksiyonel aparey Twin-blok (TWB) apareyidir.

TWB apareyinin ilk tasarımı 1988 yılında Clark tarafından yapılmıştır. Diş ve doku destekli olan TWB apareyi, dişleri ankraj üniteleri gibi birbirine bağlamak üzere dizayn edilmiştir. Fonksiyonel apareylerin pek çoğunda olduğu gibi, TWB tedavisi sonrasında da hastalarda meydana gelen en belirgin değişiklik alt keserlerin konumlarında görülmektedir. Ayrıca literatürde fonksiyonel apareylerin maksiller keserlerde retraksiyon ve alt keserlerde protrüzyon gibi istenmeyen etkilerinin olduğunu bildiren birçok araştırma vardır (6-8). TWB apareyinin ilk dizaynından bu yana, tedavi sonrasında oluşan istenmeyen etkilerin elimine edilmesi için apareyde pek çok farklı modifikasyon yapılmıştır. Alt anterior bölgenin akrilik ile kaplanması, TWB apareyi tasarımda yaygin olarak kullanılan bir modifikasyondur. $\mathrm{Bu}$ modifikasyonla alt keserlerin tedavi sırasinda proklinasyonunun ve protrüzyonunun engellenmesi hedeflenmektedir. Ancak, literatürde bu fikirle ilgili farklı görüşler mevcuttur. Bu nedenle, bu çalışmanın amac1; alt keserlerin bukkal bölgelerine uzanan akrilik kaplaması olan TWB apareyinin alt keserlerin konumları üzerine etkilerinin incelenmesidir. Hipotezimiz, farklı dizayn edilmiş iki TWB apareyinin tedavi sonrasında alt keser konumları arasında fark oluşturmadığıdır.

\section{GEREÇ ve YÖNTEMLER}

Çalışmamız, İzmir Katip ÇelebiÜniversitesi Diş Hekimliği Fakültesi Ortodonti Anabilim Dalı'na ortodontik tedavi görmek amacıyla başvuran ve TWB apareyi ile tedavi edilen hastaların sefalometrik radyografileri üzerinde gerçekleştirilmiştir. \% 80 güç, \% 5 hata düzeyi ve her grupta 5 derecelik standart sapma olacağ 1 ön görülerek örneklem büyüklüğü her bir grupta en az 14 toplamda 28 hasta olarak hesaplanmıştır. Çalışmamıza $14 \mathrm{kız}$ ve 16 erkek toplam 30 hastanın kayıtları dahil edilmiştir. Gruplara göre

- Mandibuler retrognati ile karakterize $\left(\mathrm{SNB}<78^{\circ}\right)$, iskeletsel Sınıf II ilişkiye (ANB $>4^{\circ}$ ) sahip,

- Overjeti $5 \mathrm{~mm}$ ' den fazla olan,

- Dişsel olarak 3,5 mm. veya daha fazla Sinıf II molar ve kanin ilişkisi bulunan,

- Normal büyüme yönüne sahip olan $(\mathrm{SN}-\mathrm{GoGn}<$ $38^{\circ}$,

- Pubertal büyüme atılımında; hemen öncesinde veya sonrasinda olan (CVMI III ve IV)

- Herhangi bir oral veya sistemik hastalığı olmayan,

- Daha önce ortodontik tedavi görmemiş,

- Dik yön gelişiminin normal veya azalmış olan hastaların TWB apareyi kullanımı öncesi ve sonrası sefalometrik kayıtları dahil edilmiştir.

Çalışmaya dahil edilen bireyler alt keser bölgesinde akrilik veya kroşe içeren TWB apareyi uygulanmak üzere rastgele 2 gruba ayrılmıştır.

Fonksiyonel apareyin yapilabilmesi amaciyla hastalardan sentrik ilişkide ve maksimum protrüzyon pozisyonunda overjet ölçülerek mandibulanın toplam ilerleme kapasitesinin \%70'i ve vertikal olarak da freeway space'in 2-4 milimetre üzerinde olacak şekilde mumlu kapanış alınmıştır.

TWB apareyinin tasarımında üst parçaya vestibül ark eklenerek, maksiller premolarlar ve molarların bukkal yüzeyi akrilik ile kaplanmıştır. İlk grupta alt keser bölgesinde damla kroşeler mevcutken, ikinci grupta alt keserlerin üzeri akrilik ile kaplanmıştır. Her iki grup için kullanılan apareyler Şekil 1 A ve B'de gösterilmiştir.

Çalışmada kullanılan sefalometrik radyografiler, İzmir Katip Çelebi Üniversitesi Diş Hekimliği Fakültesi Oral Diagnoz ve Radyoloji Anabilim Dalı' nda bulunan 
Orthopantomograph OP300 (Scanora/Instrumentarium, Tuusula, Finland) sefalometrik röntgen cihazı ile çekilmiştir. T0 radyografileri aparey uygulanmadan önce T1 radyografileri ise molar ve kaninlerde Sinıf I veya süper Sınıf I ilişki sağlanıp aparey çıkarıldıktan sonra alınmıştır.

\section{İstatistik yöntem}

Veriler IBM SPSS Statistics 22.0 (IBM Corp., Armonk, New York, ABD) istatistik paket programında değerlendirildi. Tanımlayıcı istatistikler Xortalama \pm standart sapma ( $\left.{ }^{-}{ }^{-} \pm s s\right)$ değerleri olarak verildi. Sayısal değişkenlere ait verilerin normal dağılımı Shapiro Wilk normallik testi ve Q-Q grafikleri ile değerlendirildi. Grupların zamana göre karşılaştırmaları tekrarlı ölçümlerde iki yönlü varyans analizi ve genelleștirilmiş doğrusal modeller yardımıyla yapıldı. Çoklu karşılaştırma testi olarak Bonferroni testi kullanıldı. $p<0.05$ değeri istatistiksel olarak anlamlı kabul edildi.

\section{BULGULAR}

Ölçümlerin tutarlılığının ve tekrarlanabilirliğinin değerlendirildiği grup içi korelasyon verilerine (Sınıf içi Korelasyon Katsayısı (ICC)) göre 1 hafta arayla yapılan her bir değişkenin ikili ölçümleri arasında yüzde 90 ve daha yüksek oranda korelasyon tespit edilmiştir. Metot hatasına ilişkin Sınıf içi Korelasyon analizinin sonuçları, çalışmadan kullanılan ölçümlerin, sonuçları etkilemeyecek ve önemli olmayan bir hata ile tekrarlanabileceğini göstermiştir.

Her iki gruptaki hastaların tedavi öncesi ve sonrası alt keser konumlarındaki değişimler Tablo I'de verilmiştir.

Alt anterior damla kroşeli TWB apareyi kullanıldığg 1 1. grupta T0-T1 zamanları arasındaki değişim IMPA $4,58 \pm 3,17^{\circ}, \quad \mathrm{L} 1-\mathrm{NB}\left({ }^{\circ}\right) \quad 5,27 \pm 3,71^{\circ}, \quad \mathrm{L} 1-\mathrm{NB}(\mathrm{mm})$ $1,57 \pm 1,82^{\circ}$ L1-APo (mm) $3,10 \pm 2,10$ ve Md1/MdOP $0,02 \pm 4,21^{\circ}$ dir. Değerlerin tanımlayıcı istatistikleri ve karşılaştırmaları Tablo II’ de özetlenmiştir.
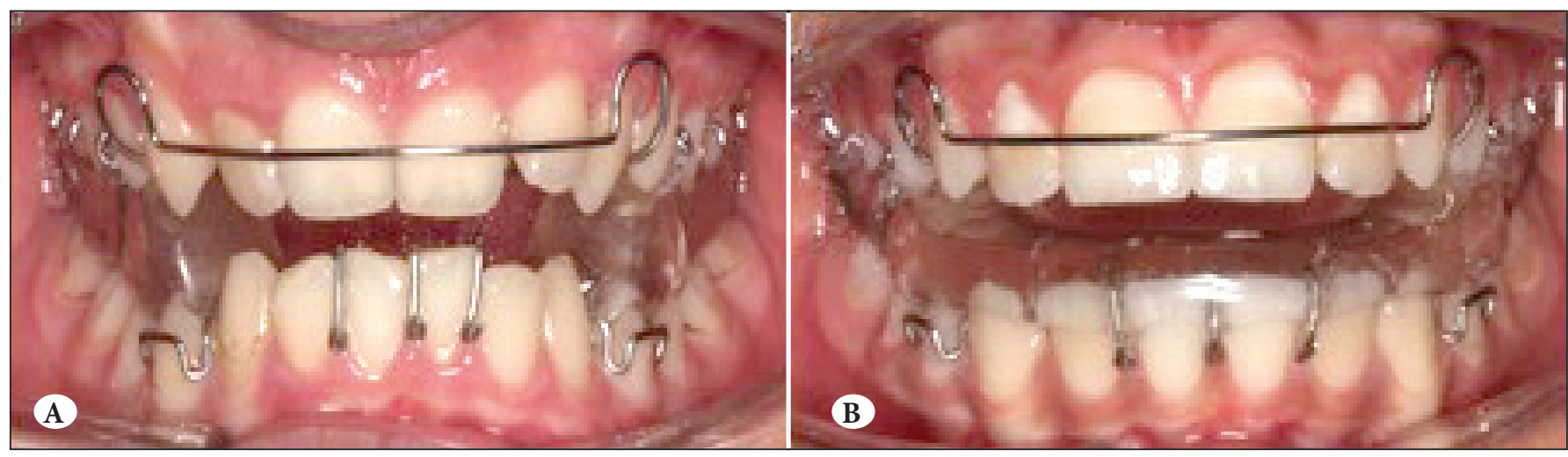

Şekil 1: A) Alt anterior cappingsiz TWB apareyi. B) Alt anterior cappingli TWB apareyi.

Tablo I: Her iki gruptaki hastaların tedavi öncesi ve sonrası alt keser konumlarındaki değişimler.

\begin{tabular}{|c|c|c|c|c|c|c|}
\hline \multirow{3}{*}{ Ölçümler } & \multicolumn{3}{|c|}{ Anterior akriliksiz TWB } & \multicolumn{3}{|c|}{ Anterior akrilik kaplı TWB } \\
\hline & T0 & T1 & \multirow{2}{*}{$p$} & T0 & T1 & \multirow{2}{*}{$p$} \\
\hline & Ort \pm SD & Ort \pm SD & & Ort \pm SD & Ort \pm SD & \\
\hline IMPA & $97,75 \pm 5,69$ & $102,33 \pm 6,19$ & $<0,001^{\star * *}$ & $97,19 \pm 7,47$ & $98,38 \pm 7,28$ & 0,206 \\
\hline $\mathrm{L} 1-\mathrm{NB}\left({ }^{\circ}\right)$ & $25,45 \pm 6,62$ & $30,72 \pm 7,02$ & $<0,001^{\star * *}$ & $24,92 \pm 5,44$ & $26,82 \pm 4,79$ & 0,075 \\
\hline $\mathrm{L} 1-\mathrm{NB}(\mathrm{mm})$ & $5,67 \pm 2,57$ & $7,24 \pm 2,87$ & $0,001^{\star *}$ & $4,86 \pm 1,81$ & $5,76 \pm 2,02$ & $0,034^{*}$ \\
\hline $\mathrm{L} 1-\mathrm{APo}(\mathrm{mm})$ & $0,42 \pm 2,60$ & $3,52 \pm 2,46$ & $<0,001^{\star * *}$ & $0,34 \pm 2,06$ & $2,54 \pm 2,53$ & $<0,001^{* * *}$ \\
\hline Md1/MdOP & $61,54 \pm 5,35$ & $61,57 \pm 4,43$ & 0,983 & $61,44 \pm 6,04$ & $64,75 \pm 4,73$ & $0,011^{\star}$ \\
\hline
\end{tabular}

Ort: Ortalama SD: Standart Deviasyon

NS: $p>0.05,{ }^{*} p<0.05,{ }^{* *} p<0.01,{ }^{* *} p<0.001$ 
Tablo II: Her iki gruptaki hastaların tedavi sonucu değişen alt keser konumlarının karşılaştırılması.

\begin{tabular}{l|c|c|c}
\hline \multirow{2}{*}{ Ölçümler } & Anterior akriliksiz TWB & Anterior akrilik kapli TWB & Ort \pm SD \\
\cline { 2 - 4 } & Ort \pm SD & $1,19 \pm 3,92$ & $0,032^{*}$ \\
\hline IMPA & $4,58 \pm 3,17$ & $1,90 \pm 4,21$ & $0,029^{*}$ \\
\hline L1-NB $\left(^{\circ}\right)$ & $5,27 \pm 3,71$ & $0,90 \pm 1,24$ & 0,299 \\
\hline L1-NB $(\mathrm{mm})$ & $1,57 \pm 1,82$ & $2,20 \pm 1,67$ & 0,245 \\
\hline L1-APo $(\mathrm{mm})$ & $3,10 \pm 2,10$ & $3,31 \pm 5,16$ & $0,042^{*}$ \\
\hline Md1/MdOP & $0,02 \pm 4,21$ & & \\
\hline $\begin{array}{l}\text { Ort: } \text { Ortalama SD: Standart Deviasyon } \\
\text { NS: } p>0.05,{ }^{*} p<0.05,{ }^{* *} p<0.01,{ }^{* * *} p<0.001\end{array}$
\end{tabular}

Alt anterior akrilik kaplamalı TWB apareyin kullanıldı̆̆ 2. grupta T0-T1 zamanları arasındaki değişim IMPA $1,19 \pm 3,92^{\circ}, \quad \mathrm{L} 1-\mathrm{NB}\left({ }^{\circ}\right) \quad 1,90 \pm 4,21^{\circ}, \quad \mathrm{L} 1-\mathrm{NB}(\mathrm{mm})$

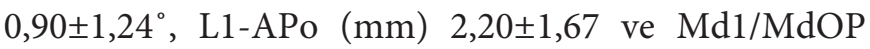
$3,31 \pm 5,16^{\circ}$ dir ve değişimler Tablo II' de gösterilmektedir. Tedavi öncesi ve sonrası alt keser konumlarını ifade eden tüm ölçümlerde istatistiksel olarak anlamlı fark bulunmuştur $(p<0,005)$.

İki grup arasındaki karşılaştırmada ise IMPA, L1/NB ve Md1/MdOP açısal değerlerinde istatistiksel olarak anlamlı fark bulunmuştur.

Elde edilen bulgular ışı̆̆ında "Farklı dizayn edilmiş iki TWB apareyinin tedavi sonrasinda alt keser konumları arasında fark oluşturmadığı" hipotezimiz reddedilmiştir.

\section{TARTIŞMA}

Çalışmamızda, alt keserlerin bukkal bölgelerine akrilik uzantısı olan TWB apareyinin alt keserlerin konumları üzerine etkilerinin incelenmiş ve bu dizaynın diğer dizayna göre alt keserlerin öne hareketini engellendiği belirlenmiştir.

Sinıf II maloklüzyonlar en sık rastlanan ve bu sebeple de ortodontistlerin en çok tedavi ettikleri maloklüzyon tipidir (9-11). Bu maloklüzyonlar çeşitli iskeletsel ve dental kombinasyonlar sonucu karşımıza çıkabildiği gibi (12), büyük oranda mandibuler iskeletsel retrüzyondan kaynaklandığı bildirilmiştir (13-17). Mandibuler retrüzyon kaynaklı Sınıf II Bölüm 1 maloklüzyonların tedavisinde sıklıkla fonksiyonel apareylerden yararlanılmaktadır (18). Fonksiyonel apareyler, mandibulanın vertikal ve sagittal olarak konumunu değiştirmesi sonucu oluşan kas kuvvetleriyle ortopedik ve ortodontik değişimler meydana getirirler (19). İskeletsel Sınıf II maloklüzyon- larda fonksiyonel ortopedik tedavinin hedefleri; ortognatik bir profilin oluşturulması, mandibuler retrognatinin azaltılması ile normal bir okluzyonun elde edilmesi ve fasiyal profilin iyileştirilmesidir (20). Çalışmamıza dahil edilen bireylerin tedavi planlarının hedefleriyle örtüşmektedir.

Çalışmamızda Clark (21) tarafından önerilen tasarım temel kabul edilerek aparey dizayn edilmiştir. Apareyde üst parçaya vestibül ark eklenmiş, maksiller premolarlar ve molarların bukkal yüzeyi ve alt keserlerin üzeri akrilik ile kaplanmıștır. Tedavi süresince alt keserlerin protrüzyonunun ve proklinasyonunun engellenmesi için üzerinin akrilikle örtülmesi sıklıkla uygulanan bir modifikasyondur (21). Toth ve McNamara (8) ise alt parçaya labial ark ve akrilik eklemiştir. Clark (21) ilk tasarımlarında alt keserlerin üzerini akrilikle kaplamış ancak bu dişlerin kesici kenarlarında oluşan dekalsifikasyonu engellemek için aparey tasarımını değiştirmiştir. Kliniğimizde rutin olarak ortodonti hastalarına oral hijyen eğitimi verilmekte ve oral hijyen takip edilmektedir. Çalışmaya dahil edilen grupta ağız hijyeninde kötüleşmeye rastlanmamıștır.

Fonksiyonel apareyler genel olarak üst çene gelişimini frenlerken alt çene gelişimini de stimule etmektedir. Ancak bu etki hem iskeletsel hem de dişseldir. Literatürde, TWB apareyi ile yapilan tedavilerden sonra alt keser eğiminin 2 ila 7.9 derece arasında artış olduğu bildirilmiştir (22). Lund ve Sandler (23) ve Tumer ve Gultan (24), yaptıkları çalıșmalarda alt keser eğimindeki değişimleri kontrol grubu ile karşılaştırmışlar ve istatistiksel olarak anlamlı fark bulmuşlardır. Antanas Šidlauskas (25) ise alt keserlerin insizal kenarlarını örten akrilik uzantının bulunduğu TWB tasarımı ile yaptığı çalışmasında, tedaviden sonra alt keserler ve mandibular düzlemin uzun ekseni arasındaki açının 3.3 derece 
arttığını bildirmiștir. Mills ve McCulloch (26) ve Toth ve McNamara (8) ise diğer çalışmaların aksine alt keser dişlerin protrüzyonunu kontrol etmek için labiyal ark ekledikleri modifiye TWB apareyi kullandıklarını ancak tedavi ve kontrol grupları arasındaki farkın istatistiksel olarak anlamlı olmadığını rapor etmişlerdir. Baysal ve Uysal (27) da TWB ve Herbst apareylerinin dişsel ve iskeletsel etkilerini araştırdıkları çalışmalarında kontrol grubu ile TWB grubu arasinda alt keser pozisyonunda herhangi bir fark bulamadıklarını ve bu sonucun, alt keser dişleri akrilik kapaklanmış TWB aparey dizaynlarıyla ilişkili olabileceğini bildirmişlerdir. Bizim çalışmamizda da benzer olarak alt keserlerin konumunu ifade eden IMPA, L1-NB $\left(^{\circ}\right)$ ve Md1/MdOP değerlerinde alt anterior akrilik uzantılı grupta diğer gruba göre istatistiksel olarak anlamlı fark bulunmuş ve alt keserlerin öne hareketinin daha az olduğu bulunmuştur.

Ortodontide tedavi sonucu kadar sonucun idame ettirilebilmesi de önemli bir konudur. TWB apareyi ile öne hareket eden alt keserler tedavi sonrasinda dudak basıncı ile upright olma eğilimindedir. Bu eğilim, çapraşıklığa yol açabilmekte ve aynı zamanda overjet ve overbite değerlerinin tedavi öncesine dönmesine sebep olabilmektedir. Genel bir kural olarak tedavi sırasinda alt keserlerin 2'mm den fazla öne alındığı durumlarda daimi retansiyon önerilmektedir (28). Bu nedenle mümkün olduğunca alt keserlerin alveol kemiğine doğru konumlandırılması ve aşırı öne hareketinin engellenmesi tedavi hedeflerinde yer almalı ve kullanılacak aparey dizaynı buna göre belirlenmelidir.

Ayrıca alt keser dişlerin alveol kemiğindeki konumu ile dişeti sağlığını da etkileyebilmektedir. Literatürde bu konuda yapılmış olan pek çok çalışma yer almaktadır. Joss-Vassalli ve ark. (29) ortodontik yaklaşımlar ve dişeti çekilmesi hakkında yaptıkları sistematik derlemede alt keserin aşırı proklinasyonunun ve alveolar prosesin dışına hareketinin o bölgede dişeti çekilme eğilimi ile ilişkili olabileceğini bildirmişleridir.

\section{SONUÇLAR}

- TWB apareyi ile tedavi sonrasinda alt keser protrüzyonu ve proklinasyonu gözlenmiştir.

- TWB apareyine alt anterior bölgesinde akrilik uzantı eklemenin alt keser proklinasyonunu engellendiği görülmüştür.

- Tedavi öncesi alt keser konumu ve eğimi tedavide kullanılacak TWB apareyinin dizaynına karar vermede dikkate alınmalıdır.

\section{KAYNAKLAR}

1. Başçiftçi FA, Demir A, Uysal T, Sarı Z. Konya yöresi okul çocuklarında ortodontik maloklüzyonların prevelansının araştırılması: Epidemiyolojik Çalışma. Turk Ortodonti Derg 2002; 15: 92-98.

2. Sayın MÖ, Türkkahraman H. Malocclusion and crowding in an orthodontically referred Turkish Population. Angle Orthod 2004; 74: 635-639.

3. Henry RG. A classification of Class II division 1 malocclusion. Angle Orthod 1957; 27: 83-92.

4. Baccetti T, Franchi L, McNamara JA Jr, Tollaro I. Early dentofacial features of Class II malocclusion: a longitudinal study from the deciduous through the mixed dentition. Am J Orthod Dentofac Orthop 1997; 111: 502-509.

5. Bishara SE, Jakobsen JR, Vorhies B, Bayati P. Changes in dentofacial structures in untreated Class 11 Division 1 and normal subjects: A Longitudinal study. Angle Orthod 1997; 1: 55-66.

6. Pancherz H. A cephalometric analysis of skeletal and dental changes contributing to Class II correction in activator treatment. Am J Orthod 1984; 85: 125-134.

7. Hägglund $\mathrm{P}$, Segerdal S, Forsberg CM. The integrated Herbst appliance-treatment effects in a group of adolescent males with Class II malocclusions compared with growth changes in an untreated control group. Eur J Orthod 2008; 30: $120-127$.

8. Toth LR, McNamara JA. Treatment effects produced by the Twin-block appliance and the FR-2 appliance of Fränkel compared with an untreated Class II sample. Am J Orthod Dentofacial Orthop 1999; 116: 597-609.

9. Sarı Z, Uysal T, Karaman A, Başçiftçi F, Üşümez S, Demir A. Ortodontik maloklüzyonlar ve tedavi seçeneklerinin değerlendirilmesi: Epidemiolojik çalıșma. Turk Ortodonti Derg 2003; 16: 119-126.

10. Sayin MO, Türkkahraman H. Malocclusion and crowding in an orthodontically referred Turkish population. Angle Orthod 2004; 74: 635-639.

11. Gelgör IE, Karaman AI, Ercan E. Prevalence of malocclusion among adolescents in central anatolia. Eur J Dent 2007; 1: 125-131.

12. Vargervik K, Harvold EP. Response to activator treatment in Class II malocclusions. Am J Orthod 1985; 88: 242-251.

13. Drelich RC. A cephalometric study of untreated Class II division 1 malocclusion. Angle Orthod 1948; 18: 70-75.

14. Renfroe EW. A study of the facial patterns associated with Class I, Class II division 1, and Class II division 2 malocclusion. Angle Orthod 1948;19:12-15.

15. McNamara JA. Components of Class II malocclusion in children 8-10 years of age. Angle Orthod 1981; 51: 177-202. 
16. Pancherz H, Zieber K, Hoyer B. Cephalometric characteristics of Class II division 1 and Class II division 2 malocclusions: a comparative study in children. Angle Orthod 1997; 67: 111-120.

17. Freitas MR, Santos MA, Freitas KM, Janson G, Freitas DS, Henriques JF. Cephalometric characterization of skeletal Class II, division 1 malocclusion in white Brazilian subjects. J Appl Oral Sci 2005; 13: 198-203.

18. Basciftci FA, Uysal T, Büyükerkmen A, Sari Z. The effects of activator treatment on the craniofacial structures of Class II division 1 patients. Eur J Orthod 2003; 25: 87-93.

19. Bishara SE, Ziaja RR. Functional appliances: a review. Am J Orthod Dentofacial Orthop 1989; 95: 250-258.

20. Baltromejus S, Ruf S, Pancherz H. Effective temporomandibular joint growth and chin position changes: Activator versus Herbst treatment. A cephalometric roentgenographic study. Eur J Orthod 2002; 24: 627-637.

21. Clark WJ. Twin Block Functional Theraphy: Applications in Dentofacial Orthopedics. 2nd ed., London, Mosby; 2002.

22. Illing HM, Morris DO, Lee RT. A prospective evaluation of Bass, bionator and Twin-block appliances. Part I: the hard tissues. Eur J Orthod 1998; 20: 501-516.
23. Lund DI, Sandler PJ. The effects of Twin Blocks: a prospective controlled study. Am J Orthod Dentofacial Orthop 1998; 113: 104-110.

24. Tumer N, Gultan AS. Comparison of the effects of monoblock and twin-block appliances on the skeletal and dentoalveolar structures. Am J Orthod Dentofacial Orthop 1999; 116: 460-468.

25. Sidlauskas A. The effects of the Twin-block appliance treatment on the skeletal and dentolaveolar changes in Class II Division 1 malocclusion. Medicina 2005; 41: 392400.

26. Mills CM, McCulloch KJ. Treatment effects of Twinblock appliance: A cephalometric study. Am J Orthod Dentofacial Orthop 1998; 114: 15-24.

27. Baysal A, Uysal T. Dentoskeletal effects of Twin Block and Herbst appliances in patients with Class II division 1 mandibular retrognathy. Eur J Orthod 2013; 36: 164-172.

28. Proffit WR, Fields HW, Sarver DM. Contemporary orthodontics. Elsevier Health Sciences; 2006.

29. Joss-Vassalli I, Grebenstein C, Topouzelis N, Sculean A, Katsaros C. Orthodontic therapy and gingival recession: a systematic review. Orthod Craniofac Res 2010; 13: 127141. 